УДК 343.3

\title{
НАКАЗАНИЕ ЗА СОЗДАНИЕ, РАСПРОСТРАНЕНИЕ ИЛИ СБЫТ ВРЕДОНОСНЫХ ПРОГРАММ ИЛИ ТЕХНИЧЕСКИХ СРЕДСТВ
}

\author{
(C) 2012 г. $\quad$ О. А. Кирбятьев
}

\section{Днепропетровский государственный университет внутренних дел}

Статья посвящения институту наказания и наказанию за создание, распространение или сбыт вредоносных программ или технических средств. В статье рассматриваются дифференииаџия ответственности и индивидуализаџия наказания. Анализируются точки зрения ряда ученьх относительно видов наказания. Автор на примере приведенной статистики применения наказания в виде лишения свободы к несовершеннолетним, с иелью гуманизации ответственности, анализирует и предлагает к применению альтернативные виды наказаний.

Ключевые слова: наказание; ответственность; дифференщиация; индивидуализация; лишение свободы; альтернативные виды ответственности.

In the article author reviews the institution of punishment for producing, distribution or sale of the harmful software or hardware. Differentiation of responsibility and individualization of punishment is also examined. A number of scientists' point of view on the types of punishment is analyzed. By the example of the statistics of assigning such kind of punishment as the custodial coercion to minors, author analyses and offers the alternative types of punishments, basing on the idea of amenability humanizing.

Key words: punishment; responsibility; differentiation; individualization; imprisonment; alternative types of responsibility.

Институт наказания выступает одним из базовых институтов уголовного права, что обусловлено его приоритетным значением в борьбе с преступностью и способностью выполнять превентивные функции. Вместе с тем, эффективность зависит от многих факторов. Избыточная, неоправданная строгость наказания за любое неправомерное действие, вместо позитивного эффекта, всегда влечет за собой страх, озлобленность человека, осознание того, что для государства он не является ценностью, отсутствие веры в возможность государственного аппарата защитить его права и законные интересы. Слишком же мягкие, гуманные наказания создают иллюзию безнаказанности, способствуют ухудшению криминогенной ситуации. Следовательно, основой функционирования наказания является его соответствие тяжести совершенного преступления с учетом личности преступника, наличия или отсутствия отягчающих обстоятельств и тому подобного.

Особенности наказания за создание с целью использования, распространения или сбыта, а также распространение или сбыт вредоносных программных или технических средств, предназначенных для несанкционированного вмешательства в работу электронно-вычислительных машин (компьютеров), автоматизированных систем, компьютерных сетей или сетей электросвязи, невозможно анализировать без четкого понимания сущности и природы наказания в целом.

Дифференциация ответственности и индивидуализация наказания длительное время остаются предметом фундаментальных научных исследований и лежат в основе закрепления в законодательстве возможных видов и 
мер ответственности, которая влечет нарушение определенной нормы, а также процесса назначения наказания.

Дифференциация ответственности выражается законодателем в правовых нормах, в которых устанавливаются возможные правовые последствия неправомерного поведения субъекта. Причем дифференциация ответственности в уголовном праве всегда охватывает дифференциацию оснований уголовной ответственности, а также вид и меру последней. То есть, в основе дифференциации находится характер общественной опасности посягательства и личность преступника. Таким образом, наблюдается двойная связь: вид санкции, ее содержание, определяются законодателем не произвольно, а на основе объективных данных. С другой стороны, от вида санкции, ее содержания, зависит и то, какие данные в деле и каким образом они должны учитываться в процессе выбора меры уголовно-правового воздействия [7]. Лицу, которое признано виновным в совершении преступления, наказание назначается в рамках, установленных законом. Следовательно, выбор форм и средств реагирования на совершенное виновным, применение средств уголовно-правового влияния преимущественно предопределено теми потенциальными возможностями, которые заложены в соответствующей санкции законодателем. Поэтому важно не только установить в законе исчерпывающий перечень видов преступлений, но и предоставить строго выдержанные, взаимосогласованные, пропорциональные тяжести преступления и личности преступника санкции. Их размер должен быть таким, чтобы, с одной стороны, судья не был поставлен в слишком узкие рамки, а с другой стороны, чтобы это пространство не было лишним, не порождало субъективизм, который имеет место, когда законодателем допускается слишком большой разрыв между минимальными и максимальными пределами санкции. Степень определения санкции предоставляет определенную свободы субъекту применения ее во время выбора вида и меры наказания. Причем в научной литературе общей теории права и теории уголовного права нет единства относительно видов санкций по степени их определенности. Отдельные ученые отмечают, что уголовное законодательство знает лишь два вида санкций: относительно определенные и альтернативные. Другие же указывают на наличие четырех видов, а именно: абсолютно определенные, относительно определенные, альтернативные и отсыльные [11].

Одни ученые выделяют три вида санкций: абсолютно определенные (в которых в четкой форме устанавливается вид и меру наказания, которое применяется к правонарушителю); относительно определенные (устанавливают минимальную и максимальную, или только максимальный предел возможного наказания); альтернативные (насчитывают несколько видов негативных последствий, из которых субъектом применения права выбирается лишь один) [1; 13]. Другие, кроме указанных выше видов, выделяют еще и кумулятивные санкции, которые предусматривают объединение нескольких видов наказаний (основных и дополнительных) [5; 12].

Можно сказать, что перечисленные точки зрения не столько противоречат друг другу, сколько являются взаимодополняющими. Поэтому, как наиболее распространенный, детальный и обоснованный вариант, можно принять за основу разделение санкций на четыре вида. При анализе санкций норм, которые предусматривают уголовную ответственность за создание с целью распространения или сбыта, а также распространение или сбыт вредоносных программных и технических средств (чч. 1, 2 ст. 361-1 УК Украины) было обнаружено, что они относятся к относительно определенным и одновременно альтернативным, то есть предусматривают широкий выбор как видов, так и меры наказания, которые предоставляют субъекту правоприменения достаточную свободу.

Индивидуализация наказания выступает своеобразной конкретизацией принципа справедливости. Принцип индивидуализации наказания является принципом уголовного права, но не уголовного законодательства, то есть он обращен не к законодателю, а к субъекту правоприменительной деятельности. Индивидуализация наказания является сложным процессом, который требует развитых аналитических способностей, знания норм закона, касающихся определения наказания, умения верно трактовать эти нормы [4].

УК Украины 2001 года четко определил 
цель наказания, предусмотрев в ч. 2 ст. 50, что цель наказания - это не только наказание, но и исправление осужденных, а также предотвращение совершения новых преступлений, как осужденными, так и другими лицами, а в ч. 3 ст. 50 - что цель наказания - это не физические страдания или унижение человеческого достоинства. Это было значительным шагом законодателя в решении проблемы цели наказания, а тем самым - в определении того конечного результата, который должен быть достигнут благодаря выполнению общих правил назначения наказания. Именно это и положено в основу ч. 2 ст. 65 УК Украины, где предусмотрено, что лицу, которое совершило преступление, должно быть назначено наказание, необходимое и достаточное для его исправления и предупреждения новых преступлений.

Критериями, направленными на индивидуализацию наказания, являются тяжесть совершенного преступления, личность виновного и обстоятельства, которые смягчают или отягчают ответственность. Такие критерии нуждаются в законодательной конкретизации и определении их влияния на меру наказания.

Как показывает зарубежный опыт, законодательство должно содержать детальное описание критериев назначения наказания, которые влияют на вид и размер наказания, то есть на его индивидуализацию [10]. На особенном значении индивидуализации наказания акцентирует внимание и В. В. Полтавец [8]. Е. Ю. Полянский отмечает, что и в зарубежных странах, в частности США, вид и размер наказания, определяется на основании учета тяжести преступления и личности виновного, что характеризуется данными о количестве судимостей за совершение преступлений в прошлом с учетом степени тяжести этих преступлений [9], а, следовательно, основные принципы назначения наказания и его цели являются общими для всех государств, независимо от их принадлежности к той или иной правовой семье.

При назначении наказания учитывается тяжесть совершенного преступления на индивидуальном уровне по фактическим обстоятельствам дела, которые характеризуют: 1) форму и виды вины, мотив и цель совершенного преступления; 2) последствия преступления, способ, место, время и обста- новку; 3) особенности объекта покушения; 4) другие обстоятельства дела, которые влияют на индивидуализацию наказания (мнение потерпевшего, поведение виновного до и после совершения преступления, отношения с потерпевшим, соучастие, множественность преступлений и др. Однако перечень обстоятельств, которые характеризуют тяжесть совершенного преступления и должны быть приняты во внимание при назначении наказания, не является исчерпывающим. Для каждого конкретного дела такие обстоятельства могут быть разными [8; 10].

Видами наказания за создание с целью использования, распространения или сбыта вредоносных программных или технических средств, а также их распространение или сбыт (ст. 361-1 УК Украины), являются: штраф, лишение свободы, исправительные работы, соединенные с дополнительным наказанием в виде конфискации программных и технических средств, предназначенных для несанкционированного вмешательства в работу электронно-вычислительных машин (компьютеров), автоматизированных систем, компьютерных сетей или сетей электросвязи, которые являются собственностью виновного лица. Наказание в виде лишения свободы за создание с целью использования, распространения или сбыта вредоносных программных или технических средств, а также их распространение или сбыт, упоминается в санкциях обеих частей ст. 361-1 УК Украины. Некоторые ученые в системе мер противодействия преступности самыми эффективными наказаниями называют лишение и ограничение свободы [15]. Возможно, такая позиция является оправданной по отношению к лицам, которые совершили преднамеренные тяжкие и особо тяжкие преступления против жизни и здоровья, а также повторно или по предварительному сговору в составе группы (преступной организации). В случае же совершения противоправного деяния впервые (при условии, что преступление не посягает на указанные выше ценности), в одиночку, такие строгие меры уголовного воздействия вряд ли являются целесообразными. На современном этапе одним из последствий концепции строгого наказания в Украине есть традиционно высокий удельный вес наказания в виде лишения свободы (свыше 30\%) и 
один из наивысших в мире показателей числа приговоренных в расчете на количество населения.

Определенными учеными делается вывод, который полностью поддерживается автором, о недостаточной эффективности этого вида наказания и необходимости пересмотра политики государства в этой сфере в сторону последовательного смягчения [14].

Отдельную проблему составляет применение лишения свободы к несовершеннолетним, особенно в случае совершения ими преступлений, не связанных с нарушением права на жизнь, здоровье, половую неприкосновенность. Создание с целью использования, распространения или сбыта вредоносных программных или технических средств, а также их распространение или сбыт не относится к категории тяжких насильственных преступлений, поэтому средства борьбы с ними должны быть совсем другими, особенно когда субъект правоприменительной деятельности имеет дело с несовершеннолетними лицами. Хотя и законодатель и судьи придерживаются другой позиции, которая следует, как из анализа правоприменительной практики, так и из текста УК Украины, и подтверждается следующим: для законодательства большинства стран постсоветского пространства общим является использование достаточно строгих мер уголовной ответственности, в том числе относительно несовершеннолетних. Так, опыт Российской Федерации демонстрирует, что наиболее применяемым наказанием к несовершеннолетним является именно лишение свободы, случаи применения которого стали постепенно сокращаться в количественных показателях лишь в последнее время, и совсем незначительную часть составляют штраф и исправительные работы [6]. Другие же наказания к несовершеннолетним вообще не применяются. Подобная ситуация прослеживается и в Украине, за исключением того, что в этой стране к несовершеннолетним не применяется и штраф. Статистические данные свидетельствуют о том, что в 20052008 годах к лицам, которые совершили преступление в возрасте до 18 лет, судами применялось исключительно лишение свободы на определенный срок, к которому было приговорено: в 2005 г. - 20,7\%, в 2006 г. - 19,3\%, в 2007 г. - 21,4\%, в 2008 г. - 19,6\% несо- вершеннолетних. Было освобождено от наказания с испытанием соответственно: 72,3\%, $73,1 \%, 69,8 \%, 69,9 \%$. Относительно других дела были закрыты с применением принудительных мер воспитательного характера. В первом полугодии 2009 года к лишению свободы на определенный срок приговорили 23\% несовершеннолетних; к общественным работам - 2,6\%; освобождено от наказания с испытанием - 65,6\%, к другим применены принудительные меры воспитательного характера [2].

Главной при назначении наказания должна быть именно его неотвратимость и соответствие строгости наказания степени тяжести совершенных противоправных действий.

Из этого следует, что по отношению к созданию с целью использования, распространения или сбыта вредоносных программных или технических средств, а также их распространению или сбыту, самыми эффективными и такими, которые полностью отвечают степени тяжести данных преступных посягательств, могут стать альтернативные наказания, не связанные с лишением свободы. Такие наказания способствуют лучшей ресоциализации осужденного и его интеграции в общество, нуждаются в меньших материальных расходах, ведут к уменьшению количества лиц, которые находятся на государственном иждивении и содействуют развитию процессов гуманизации, которые происходят в обществе. Наказание в виде исправительных работ, лишения права занимать определенные должности или заниматься определенной деятельностью, общественных работ, а также мероприятия профилактически-воспитательного влияния, по своей сути, имеют не только карательный, но и социальный, экономический смысл, поскольку они позволяют осужденному сохранить позитивные семейные связи, профессиональные навыки и не изолировать его от привычного социального окружения [3].

Квалификация создания с целью использования, распространения или сбыта вредоносных программных или технических средств, а также их распространение или сбыт, осуществляется согласно ч. 1 ст. 361-1, с учетом специфики данных преступлений. Лишение свободы, именно по причине его значительной строгости не только не выпол- 
нит функций и целей, которые возлагаются на наказание, а лишь усилит антисоциальные склонности лица. Поэтому, по нашему мнению, целесообразно назначение наказания в виде лишения свободы за преступления данной категории лишь при наличии тяжких последствий, когда использование вредных программных или технических средств, например, приведет к причинению тяжких телесных повреждений или гибели человека (что полностью может случиться при незаконном вмешательстве в работу ЭВМ, автоматизированной системы, компьютерной сети, с помощью вредных программ или технических устройств, которые существенно нарушают их нормальную работу). Примером этому может быть вмешательство в нормальную работу системы электронного управления ядерной станцией, нарушение работы которой вполне может привести к указанным тяжким последствиям.

В случае наступления перечисленных негативных последствий необходимо учитывать все обстоятельства совершения преступления, а именно: форму вины, разграничение наказания за преднамеренные и неосторожные действия при использовании или распространении вредных программных и технических средств. В процессе воспроизведения событий, связанных с созданием с целью использования, распространения или сбыта вредоносных программных или технических средств, необходимо использовать такие криминализационные факторы, как категорию уничтоженной, перекрученной, модифицированной или блокированной компьютерной информации; особенности состояния субъекта в момент совершения посягательства, его последующее поведение, другие факторы, присущие ситуации. Это позволит учесть человеческий фактор при квалификации неосторожных действий, предусмотренных ст. 361-1. К тому же, даже при наличии умысла деяния, преступник далеко не всегда желает наступления последствий и часто не осознает возможность их наступления.

Некоторые ученые считают возможным установление одинакового вида и меры наказания за преднамеренные и неосторожные информационные правонарушения, в том числе применение такого вида наказания как лишение свободы. Например, как считает
Е. М. Щербина, наивысшая мера наказания для лиц, которые совершили преступления с использованием средств компьютерной техники по неосторожности, не должна превышать восьми лет лишения свободы [16]. Это является достаточно суровым наказанием относительно неосторожных незаконных деяний. Такой срок Е. М. Щербина никак не обосновывает. По нашему же мнению, применение лишения свободы относительно неосторожных компьютерных преступлений, в том числе за создание с целью использования, распространения или сбыта вредоносных программных или технических средств, а также их распространение или сбыт, вообще нецелесообразно, что обусловливается особенностями работы каждой отдельной автоматизированной системы, компьютерной сети, которые правонарушитель чаще всего не может предусмотреть (хотя должен, учитывая определенный уровень технических знаний и навыков).

\section{Выводы}

Наказание выступает одним из базовых институтов уголовного права, что обусловлено его ведущим значением в борьбе с преступностью и способностью выполнять превентивные функции. Дифференциация ответственности и индивидуализация наказания лежат в основе закрепления в законодательстве возможных видов и мер ответственности, которые влекут нарушение определенной нормы, а также процесс назначения наказания. Главное - не только установить в законе исчерпывающий перечень видов преступлений, но и предоставить строго выдержанные, взаимосогласованные, пропорциональные тяжести преступления и личности преступника санкции.

Индивидуализация наказания является сложным процессом, который требует развитых аналитических способностей, знания норм закона, умения верно их трактовать. Критериями, направленными на индивидуализацию наказания, являются тяжесть совершенного преступления, личность виновного и обстоятельства, которые смягчают или отягчают ответственность.

Главной при назначении наказания должна быть именно его неотвратимость и соответствие строгости наказания степени тяже- 
сти совершенных противоправных действий.

Целесообразным и обоснованным будет назначение наказания в виде лишения свободы за создание, с целью использования, распространения или сбыта вредных программных или технических средств, а также их распространение или сбыт, лишь при наличии тяжких последствий, когда использование вредных программных или технических средств, например, приведет к причинению тяжких телесных повреждений или гибели человека.

Автор считает нецелесообразным применение лишения свободы относительно неосторожных компьютерных преступлений, в том числе за создание с целью использования, распространения или сбыта вредных программных или технических средств, а также их распространение или сбыт, в связи с особенностями работы каждой отдельной автоматизированной системы, компьютерной сети. Самыми эффективными и такими, которые полностью отвечают степени тяжести данных преступных посягательств, могут стать альтернативные наказания, не связанные с лишением свободы: исправительные работы, лишение права занимать определенные должности или заниматься определенной деятельностью, общественные работы, а также мероприятия профилактически-воспитательного влияния, которые, по своей сути, имеют не только карательный, но и социальный, экономический смысл.

\section{Литература}

1. Алексеев C. С. Государство и право: Начальный курс. / 2-е изд., перераб. и доп. М.: Юрид. лит., 1994. - 190 с.

2. Аналіз стану здійснення судочинства судами загальної юрисдикції в 2001-2009 роках (за даними судової статистики) [Электронный ресурс] / Інформаційний сервер Верховного суду України. - Режим доступа: http://www.scourt.gov.ua, свободный (25.02.2010). - Загл. с экрана.

3. Богатирьов I. Г. Кримінальні покарання, не пов'язані з позбавленням волі (теорія і практика їх виконання кримінально-виконавчою інспекцією). Автореф. дисс. ... доктора юрид. наук: 12.00.08. - К.: Київський національний ун-т внутрішніх справ, 2006. - 32 с.
4. Велиев С. А. Индивидуализация уголовного наказания: монография. / С. А. Велиев, А. В. Савенков. - М.: РОХОС, 2005. - 216 c.

5. Веремеенко И. И. Административноправовые санкции. - М., 1975. - 139 с.

6. Ибрагимова А. М. Система наказаний несовершеннолетних: проблемы регулирования и практика применения. // «Черные дыры» в российском законодательстве. 2006. - №1. - С. 379-386.

7. Кругликов Л. Л. Дифференциация ответственности в уголовном праве. / Л. Л. Кругликов, А. В. Васильевский. - СПб.: Издательство «Юридический центр Пресс», 2002. $-300 \mathrm{c}$.

8. Полтавець В. В. Загальні засади призначення покарання та їх кримінально-правове значення. Автореф. дисс. ... канд. юрид. наук: 12.00.08. - К.: Інститут держави і права ім. В. М. Корецького, 2005. - 20 с.

9. Полянський $С$. Ю. Призначення покарання за кримінальним правом США. Автореф. дисс. ... канд. юрид. наук: 12.00.08. Одесса: Одеська національна юридична академія, 2007. - 17 с.

10. Сахарук T. В. Загальні засади призначення покарання за кримінальним правом України та зарубіжних країн: порівняльний аналіз. Автореф. дисс. ... канд. юрид. наук: 12.00.08. - К.: Київський національний ун-т ім. Тараса Шевченка, 2006. - 18 с.

11. Советское уголовное право. Общая часть. / Под ред. Н. А. Беляева, М. И. Ковалева. - М., 1977. - 478 с.

12. Теория государства и права: учебник. / Под ред. Р. А. Ромашова. - СПб.: Юридический центр «Пресс», 2005. - 630 с.

13. Хахулина K. C. Теория государства и права в схемах и определениях: учебн. пособ. / К. С. Хахулина, В. А. Малыга, И. В. Стадник. - 2-е изд., перераб и доп. - Донецк: Норд-Пресс, ДонНУ, 2008. - 344 с.

14. Черкасов С. В. Кримінологічна концепція альтернативних мір покарання. Автореф. дисс. ... канд. юрид. наук: 12.00.08. - Одесса: Одеська національна юридична академія, 2005. - 19 с.

15. Шинальський О. I. Покарання в системі засобів протидії злочинності. Автореф. дисс. ... канд. юрид. наук: 12.00.08. - К.: Інститут держави і права ім. В. М. Корецького, 2003. - $20 \mathrm{c}$. 
16. Щербина E. М. Проблемы пенали- 12.00.08. - Владивосток: Дальневосточный зации неосторожных технических престу- государственный ун-т, 1994. - 21 с. плений. Автореф. дисс. ... канд. юрид. наук:

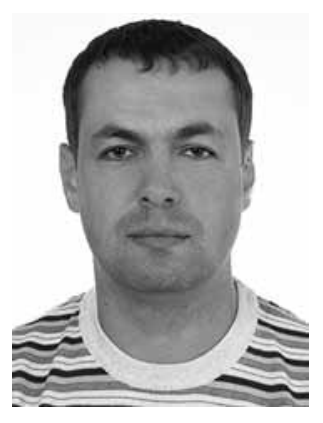

Олег Александрович Кирбятьев - майор милиции, адъюнкт кафедры уголовного права и криминологии Днепропетровского государственного университета внутренних дел.

Oleg Aleksandrovich Kirbatyev - police major, adjunct at the Penal Law and Criminology department of the Dnepropetrovsk State University of Internal Affairs.

69124, Украина, г. Запорожье, ул. Курузова, 11А, кв. 82

11A Kuruzova st., app. 82, 69124, Zaporozhye, Ukraine

Тел.: +38 (063) 463-41-72; e-mail: cobrian@mail.ru 